\title{
Decision Support Model for Managing Academic Workload in State Universities and Colleges
}

\author{
Lorna T. Soriano, Joni Neil B. Capucao, and Thelma D. Palaoag
}

\begin{abstract}
Decision Support is crucial in the function of administrators as decision makers in any academic institution. This study developed a decision support model for managing college academic workload in State Universities and Colleges (SUC) using a feed-forward Artificial Neural Network (ANN) trained by a back propagation algorithm. The DS model offers a flexible and strong predictive ability in assigning and distributing academic workloads efficiently.

The researchers' neural network based decision support model in assigning qualified faculty to handle specific courses in processing and identifying the best teacher to handle a particular subject requiring quality potentialities, its impact would transcend beyond what an ordinary teacher can afford to deliver. The model being statistically, technologically and scientifically based, pedagogically the academe in general can meet the expected learning performance level.
\end{abstract}

Index Terms-Decision support model, decision making, neural network, workload management.

\section{INTRODUCTION}

Decisions are important. It can spell the difference between success and failure. Since making the right decisions is of utmost importance for companies and institutions, methods and techniques with the objective of giving support for decision making has been given more attention recently. Decision support is crucial in the function of administrators as decision makers in any Higher Education Institution (HEI) Academic decision-making may require extensive analysis of large data volume emerging from multiple sources or processes. These generated data and information can be transformed and integrated into a data warehouse which can be used in measuring, evaluating and planning academic workload [1]. Oftentimes, problems encountered in making decision include unavailability of the data in an appropriate form and lack of tools and approaches for its evaluation [2]. Higher education institutions such as State Universities and Colleges (SUC) are experiencing the need of effective decision support tools to accurately inform them, and assist in all managerial processes. Such tools would have the role to a) supervise existing activities: educational activities, processes, or resources which entail students, teaching and auxiliary staff, curricula, syllabi, and all administrative services; b)

Manuscript received November 30, 2017; revised January 2, 2018. This work was supported in part by Partido State University, Bicol State College of Applied Sciences and Technology.

L. T. Soriano is with Bicol State College of Applied Sciences and Technology, City of Naga, Philippines (e-mail: Ltsoriano@biscast.edu.ph).

J. N. B. Capucao is with Partido State University, Goa, Camarines Sur, 4421, Philippines (e-mail: jonineil.capucao@parsu.edu.ph).

T. D. Palaoag is with the University of the Cordilleras, Baguio City, Philippines (e-mail: tpalaoag@gmail.com). collect data on education and research processes; c) develop a collaborative environment, monitor its activities and measure accomplishments; present important information to assist constant evaluation, and alternatives for performance; and lastly d) offer feedback for constant development [3].

One aspect that administrators make vital decision is on academic workload management. Managing of academic workload involves assigning and distributing teaching resources efficiently [2] such as faculty, students, courses, teaching loads, facilities, laboratories, etc. for the educational framework to operate smoothly. Generally, administrators are charged with implementing strategies including models that attempt to distribute complex academic workloads fairly and transparently in order to meet institutional goals [4]. The common problem that HEIs encounter on workload management is the proper and timely determination on the adequacy of manpower and facilities available for existing programs or proposed programs to open. This results to bigger predicaments like delayed opening of classes, insufficient number of classrooms or laboratories, and scarcity of qualified faculty to teach in particular courses. Consequently, it requires complex interrelation of requirements such as matching qualified faculty with courses to handle or number of available laboratory with the course requirement. In this paper, the authors addressed the problem of managing academic workload by developing a decision-support model that can be used as the basis for the academic workload decision support system.

A decision support system (DSS) is a computer-based system that when supplied with appropriate parameters, enables efficient management of the given information and accurately predicts effects of possible decisions [5]. A DSS for higher education should collect academic processes information, provide feedback for their improvement, and offer decision-making support with high integration and direct interaction with all the domains of the problem [3]. This should allow simulation and evaluation of various proposals and scenarios in SUCs leading to significant acceleration of planning procedures, deepens the insight into data and consequently, providing efficient academic management.

Intelligible methodology, precise computational model, complete and consistent data basis and friendly output presentation are of paramount importance for advanced decision support [2]. Various academic DSS have been previously proposed for purposes such as capacity utilization [2], forecasting students' grades [6], admission management [7], course scheduling [8], and university management [9]. These studies brought awareness on the advantages of DSS to academic decision makers.

Focusing on the workload management which requires 
various parameters, the role and contribution of each conceptual design parameter have been identified. These include program requirements based on the CHED Memo Orders (CMO), faculty profiles, and school facilities such as classrooms and laboratories. The CMO dictates the policies, standards and guidelines in offering a program in HEIs. It includes the minimum curriculum requirements, qualification of faculty and admin, and laboratories/classrooms requirements. The SUCs are maintaining records of their faculty profile and school facilities and these should match the requirements laid in the CMO to confidently offer a specific program. But unfortunately, administrators find difficulty to interrelate these parameters efficiently thus oftentimes resulting to poor workload management. This study aimed to develop a decision support model for managing college academic workload in Partido State University (PSU) and Bicol State College of Applied Sciences and Technology (BISCAST). The fundamental processes and elements involved in managing academic workload in the College of Engineering of two SUCs were identified. Moreover, the components and functionalities of the proposed DS model were specified. Finally, its efficiency was determined through various testing using actual workload data.

The proposed DS model targets to support the administrative task of managing workload by offering a comprehensive approach to deal with various conditions. Consequently, this can be used as basis for developing Intelligent Decision Support System for academic workload management.

The conceptual framework, shown in Fig. 1, guided the researchers in this study. The conceptual paradigm shows the components of the DS Model.

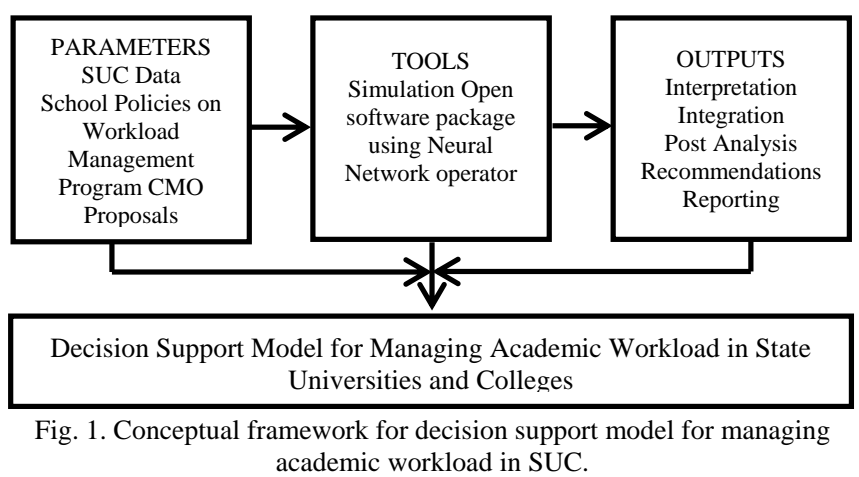

The parameters include the existing academic data and records of the SUC such as programs offered, courses, faculty profile, facilities and laboratories; school policies related to academic workload; program CMO and inputs based on proposals

In training and evaluating the model, a tool was used to produce outputs for interpretation, integration, post analysis and recommendations.

\section{MethodOLOGY}

The research design utilized in this study is developmental since the researchers intended to develop a decision support model that would facilitate efficient academic workload management.
To obtain a clear picture of the fundamental processes involved in workload management in BISCAST and PSU, the researchers conducted interviews with the vice president of academic affairs, deans and program chairperson in the College of Engineering. Data elements were acquired from the forms and documents collected from the college.

The gathered information were used in designing the architectural framework of the DS model. In this process, the components and their relationships and connections were identified. After which the design of the database structure and the entity relationship diagram that illustrates the interrelationship of the entities was done.

In training and evaluating the model, an open software package was utilized using back propagation learning algorithm based on Artificial Neural Network.

\section{A. Artificial Neural Network}

An Artificial Neural Network (ANN) is a computational model that is inspired by the functional aspects and structure of biological neural networks [10]. Structurally, this model can be represented as an interconnection of many independent individual processing elements that behave similarly in certain respects to the interconnection of individual neurons in the brain [11].

Neural networks are basically organized into three parallel layers. These layers are made up of a number of interconnected nodes which contain an activation function. The first layer called input layer contains independent variables, the second called hidden layer contains processing units, and the third is the output layer which contains the dependent variables. Patterns are presented to the network via the input layer, which communicates to one or more hidden layers where the actual processing is done via a system of weighted connections. The hidden layers then link to an output layer where the answer is output as shown in Fig. 2. In most cases an ANN is an adoptive system that changes its structure based on external or internal information that flows through the network during the learning phase.

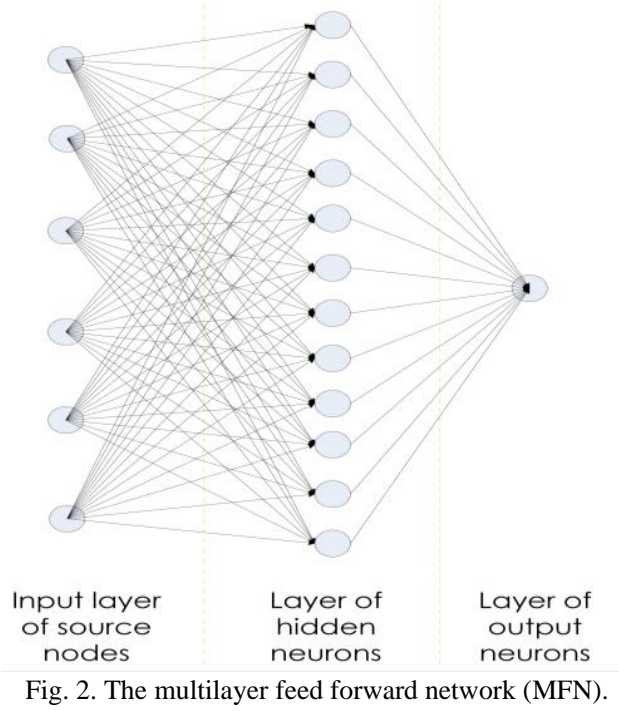

For a given neural $k$, let there be $m+1$ inputs with signals $x_{0}$ through $x_{m}$ and weights $w_{0}$ through $w_{m}$. Usually, the $x_{0}$ input is added the value +1 , which makes it a bias input with $w_{k 0}=b_{k}$. This leaves only $m$ actual inputs to the neuron: from $x_{1}$ to $x_{m}$. 
The output of the $k$ th neuron is:

$$
y_{k}=\varphi\left(\sum_{j=0}^{m} w_{k j} z_{j}\right)
$$

where $\varphi$ (phi) is the activation function.

In ANN model, the authors used nonlinear sigmoid functions, specifically the logic function:

$$
f(v)=\frac{1}{1+e^{-v}}
$$

as activation functions for the hidden nodes and linear activation functions at the output. In training and evaluating the model, RapidMiner open software package was utilized.

\section{B. Back Propagation Algorithm}

Back propagation is the most widely applied learning algorithm for neural networks. It learns the weights for a multilayer network, given a network with fixed set of weights and interconnections [12]. The back propagation algorithm is a supervised learning method which can be divided into two phases: propagation and weight update. The two phases are repeated until good performance of the network is achieved. Although this is an iterative and maybe somewhat time consuming algorithm, when trained on adequate samples it gives good results in practice. Recently, neural network techniques have been applied in many areas, such as pattern recognition, knowledge databases for stochastic information, robotic control, and financial decision making [11].

In this study, the back propagation learning algorithm based on a feed forward network was used. Basically, the feed forward concept indicates that the flow of the network information is only in one direction, from input nodes, through the hidden nodes toward output nodes.

The network is trained by presenting an input pattern value, performing the calculations successively through the network until an output value is obtained. The training starts with random weights and bias neuron is added to the hidden layer to ensure that the network will always have an output value even when the input value is zero. The goal is to adjust these weights to achieve minimal error. The function error is defined as

$$
E=\sum_{k} \frac{1}{2}\left(t_{k}-y_{k}\right)^{2}
$$

where $t_{k}$ is the expected output and $y_{k}$ is the actual output. The error is then fed back through the network. Using this information, the algorithm adjusts the weights (weight correction) throughout the entire network structure until either the objective function (sum of the squared prediction errors on the training set) is sufficiently close to zero or the default number of iterations is reached.

The weight correction is defined by

$$
\Delta w_{k j}=n\left(t_{k}-y_{k}\right) \varphi^{\prime}\left(z_{k}\right) z_{j}
$$

where $n$ is the learning rate, $\left(t_{k}-y_{k}\right)$ is the corresponding error signal, derivative $\varphi^{\prime}\left(z_{k}\right)$ of the associated activation function and $z_{j}$ is the input signal of neuron $\mathrm{k}$.

\section{RESULTS AND DisCUSSION}

\section{A. Fundamental Academic Workload Elements and Processes}

The Work Instruction of the academic process of BISCAST and PSU define the process starting from curriculum planning up to students' graduation. Based from the work instruction, a general flow of academic workload planning and assignment as shown in Fig. 3, is identified. A program curriculum is designed by the Curriculum Development Committee based on CHED Memorandum Order (CMO). In the CMO, the minimum requirements for the program are dictated. Initially, the compliance of the requirements can be determined by checking against the existing resources of the school.

The assignment of individual course to faculty as well as the facility to be used is done by the college dean or program/area chairperson based on the faculty profile and list of facilities, respectively.

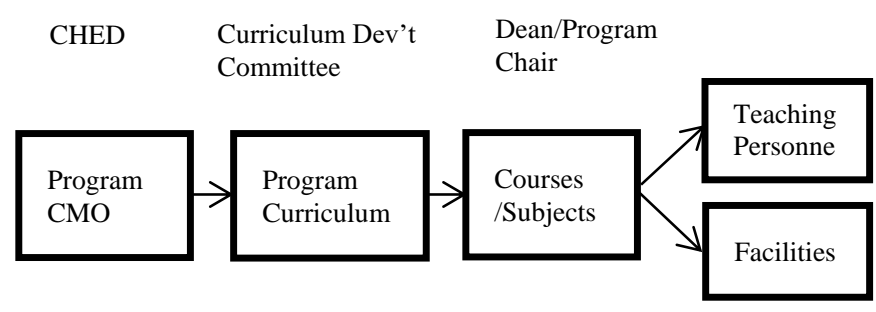

Fig. 3. General flow of academic workload planning and assignment.

The major data elements identified in the academic workload management were the curriculum, courses, teaching personnel and facilities. The CMO is used as the basis of requirements for a particular program.

Moreover, a detailed process of actual workload management was obtained during the interview with the concerned administrators.

\section{B. DS Model and Functionalities}

The proposed DS model comprises of three (3) sections namely: data management, model management, and knowledge management as shown in Fig. 4.

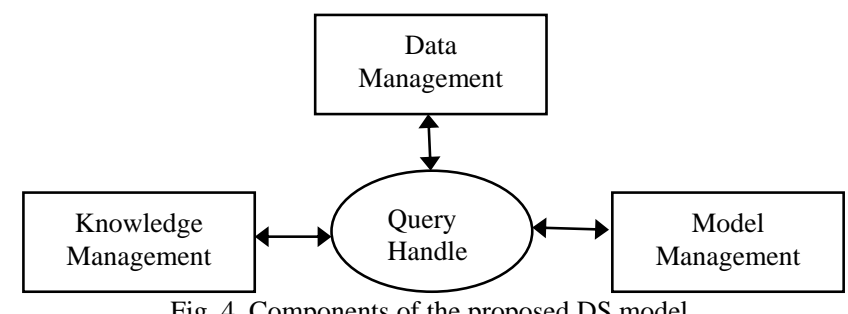

Fig. 4. Components of the proposed DS model.

The functionalities of each of the sections [13] are summarized in Table I.

The Decision Support model utilizes an Artificial Neural Network architecture which is a multi-layer feed forward network as shown in Fig. 5. The workload data of the College of Engineering for four (4) semesters was used as the dataset in the simulation process. This dataset is consists of the following attributes: subject/course, instructor, degree, 
specialization, research and trainings. Input layer represents the six parameters used in the study. A default hidden layer with sigmoid and size equal to (number of attributes + number of classes) $/ 2+1$ is added.

TABLE I: FUNCTIONALITY OF THE DS MODEL COMPONENTS

\begin{tabular}{|c|c|}
\hline Component & Functionality \\
\hline $\begin{array}{l}\text { Data } \\
\text { Management }\end{array}$ & $\begin{array}{l}\text { Consists of database for storing the data and information } \\
\text { gathered. }\end{array}$ \\
\hline $\begin{array}{l}\text { Model } \\
\text { Management }\end{array}$ & $\begin{array}{l}\text { This captures the analytical model adopted employed to } \\
\text { solve the decision-making problem. Various parameters } \\
\text { associated with the decision-making problem are } \\
\text { provided as input and the model finds the optimal } \\
\text { solution to the problem for the present set of inputs. }\end{array}$ \\
\hline $\begin{array}{l}\text { Knowledge } \\
\text { Management }\end{array}$ & $\begin{array}{l}\text { Consists of the rules and knowledge for the domain. } \\
\text { Initially, the knowledge and rule bases are provided with } \\
\text { information obtained from previous data or from } \\
\text { simulation processes. The knowledge base is updated } \\
\text { with new knowledge and rules as it gain information } \\
\text { from the environment. }\end{array}$ \\
\hline $\begin{array}{l}\text { Query } \\
\text { Handler }\end{array}$ & $\begin{array}{l}\text { Obtains the relevant information from all the } \\
\text { components and returns a single coherent reply. }\end{array}$ \\
\hline
\end{tabular}

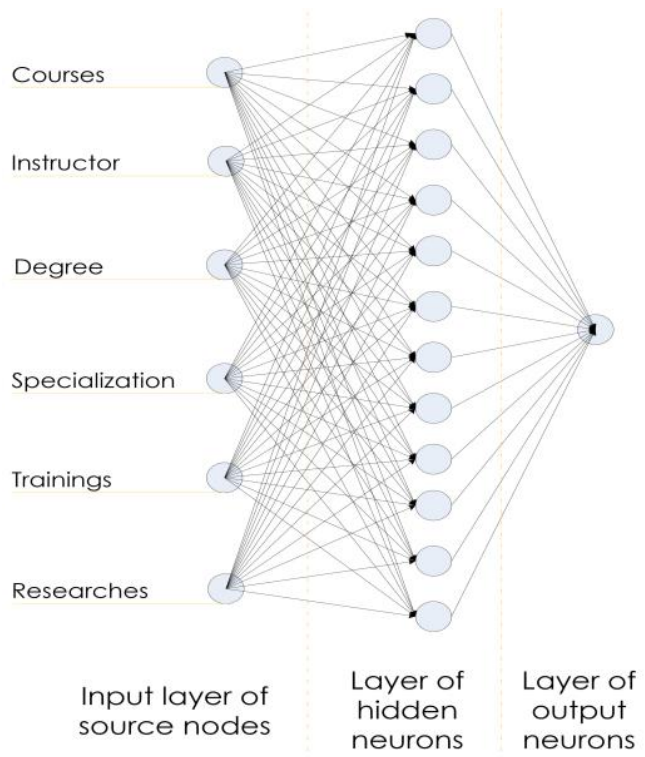

Fig. 5. Artificial neural network architecture.

The dataset was segregated into 70 percent training set and 30 percent test set. Prior to the simulation, the researchers manually evaluated and computed the sum of trainings and researches that are related to the course, and assigning also the value of 1 or 0 if the teacher's specialization is suited to the course. Then, all nominal values both in the training set and test set were converted to numeric. The researchers used 0.7 learning rate with training cycles of 500 for the neural network simulation which was taken from the experimental finding of best values as shown in Table II.

Neural network evaluation will determine its capability to accurately predict the workload assignment. The focus in evaluating the system's performance will be generalization. It refers to the ability of a trained ANN to respond appropriately to input not used during the training process. The test data served as input to the ANN during evaluation.

A prototype of the model was implemented using Python
3.0 to test its accuracy. One metric used to determine how well a classifier performs is called the $\mathrm{fl}$ score which is a number between zero and one. It is analogous to a percentage, with 1 being the equivalent of 100 percent predictive accuracy. Table III and IV shows the sample accuracy result of the implementation for the Training Data and the Dataset.

\begin{tabular}{ccc}
\multicolumn{2}{c}{ TABLE II: ACCURACY RESULT ON TRAINING/TEST DATA } \\
\hline Learning Rate & Iteration & Accuracy $(\%)$ \\
\hline 0.3 & 500 & 0.864 \\
0.3 & 1000 & 0.869 \\
0.3 & 2000 & 0.845 \\
0.7 & 500 & 0.914 \\
0.7 & 1000 & 0.857 \\
0.7 & 2000 & 0.857 \\
0.9 & 500 & 0.854 \\
0.9 & 1000 & 0.870 \\
0.9 & 2000 & 0.852 \\
\hline
\end{tabular}

TABLE III: FEED FORWARD PROPAGATION TRAINING DATA RESULT

\begin{tabular}{|c|c|c|c|c|c|}
\hline $\begin{array}{c}\text { Test 1 } \\
\text { Average }\end{array}$ & $\begin{array}{c}\text { Test 2 } \\
\text { Average }\end{array}$ & $\begin{array}{c}\text { Test 3 } \\
\text { Average }\end{array}$ & $\begin{array}{c}\text { Test 4 } \\
\text { Average }\end{array}$ & $\begin{array}{c}\text { Test 5 } \\
\text { Average }\end{array}$ & $\begin{array}{c}\text { Aggregate } \\
\text { Mean }\end{array}$ \\
\hline 0.9184 & 0.9278 & 0.8375 & 0.9446 & 0.9426 & 0.9105 \\
\hline
\end{tabular}

TABLE IV: CROSS-VALIDATION OF DATA RESULT
\begin{tabular}{|c|c|c|c|c|c|}
\hline $\begin{array}{c}\text { Test 1 } \\
\text { Average }\end{array}$ & $\begin{array}{c}\text { Test 2 } \\
\text { Average }\end{array}$ & $\begin{array}{c}\text { Test 3 } \\
\text { Average }\end{array}$ & $\begin{array}{c}\text { Test 4 } \\
\text { Average }\end{array}$ & $\begin{array}{c}\text { Test 5 } \\
\text { Average }\end{array}$ & $\begin{array}{c}\text { Aggregate } \\
\text { Mean }\end{array}$ \\
\hline 0.9038 & 0.9423 & 0.8269 & 0.9615 & 0.9231 & 0.9115 \\
\hline
\end{tabular}

With the test results of near 1 , it is therefore established that the system's predictive performance is almost accurate. In addition, the result of the back propagation training on the multi-layered neural network such that it can learn the appropriate internal representations to allow it to learn the mapping of courses to a teacher showed zero cost of error for all the test conducted.

\section{CONCLUSION}

From the Feed Forward Propagation Dataset result of 0.9110 which has been derived from the tabulation of the aggregate mean and the average mean of both training data (0.9105) and test data (0.9115) showed no significant difference when tested for significance at alpha 0.05 that indicated $\mathrm{F}=0.000099$ while $\mathrm{F}$ critical $=5.317655$ suggested that the model was found in terms of accuracy level, near perfection as such it would mean proper distribution of teaching resources for a more efficient workload management. The researchers' neural network based decision support model in assigning qualified faculty to handle specific courses in processing and identifying the best teacher's choice to handle a particular subject requiring quality potentialities, its impact would transcend beyond what an ordinary teacher can afford to deliver. Therefore, the model being statistically, technologically and scientifically based, pedagogically the academe can meet the expected learning performance level.

For future study, the authors recommend for the adoption of the model in a fully functional decision support system.

\section{ACKNOWLEDGMENT}

It is with immense gratitude that we acknowledge the support and help of PSU and BISCAST Office of the Vice 
President, HRMO, College Deans, Program Directors and IT faculty for accommodating and accepting new ideas - mam Jo, mam Cing, sir Joe, mam Jane, sir Mike, Sir Leo and Sir Marlo, respectively.

To the staff of PSU College of Engineering and Technology and BISCAST College of Engineering and Architecture for providing copy of the Work Instruction, Faculty Profile, Program of Study, Sample Work Load, and other Forms.

And, most especially we are very thankful to the Almighty God who leads, guides, and gives us the strength to finish this research.

\section{REFERENCES}

[1] Zilli and N. Trunk-Sirca, "DSS for academic workload management," International Journal of Management in Education, vol. 3, issue 2, 2009.

[2] S. Vinnik and M. H. Scholl, "Decicion support system for managing Educational capacity utilization in universities," IEEE Transactions on Education, pp. 143-150, 2007.

[3] V. P. Bresfelean and N. Ghisolu, "Higher education decision making and decision support systems," WSEAS Transactions on Advances in Engineering Education, vol. 7, issue 2, 2010.

[4] S. Hornibrook, "Policy implementation and academic workload planning in the managerial university: Understanding uinintended consequences," Journal of Higher Education Policy and Management, vol. 34, 2012.

[5] V. Serifi, S. Randic, and P. Dasic, "Examples of software tools for decision support system (DSS) based on modern technologies," presented at 2nd International Conference ICQME 2007, Milocer, Montenegro, 2007.

[6] S. B. Kotsiantis, "Use of machine learning techniques for educational purposes: a decision support system for forecasting students' grades," Artif Intell Rev., 2012, vol. 37, p. 331.

[7] R. Vohra and N. N. Das, "Intelligent decision support systems for admission management in higher education institutes," International Journal of Artificial Intelligence \& Applications, vol. 2, no. 4, 2011.

[8] J. Miranda et al., "A web architecture based decision support system for course and classroom scheduling," Decision Support Systems, vol. 52 , issue 2, January 2012, pp. 505-513.

[9] L. F. Robledo et al., "Hybrid simulation decision support system for university management," in Proc. the 2013 Winter Simulation Conference: Simulation: making Decisions in a Complex World," 2013, pp. 2066-2075.

[10] Neural net (RapidMiner Studio Core). (2017). RapidMiner Documentation. [Online]. Available: https://docs_rapidminer.com/studio/operators/modeling/predictive/ne ural_nets/neural_net.html.
[11] N. Klintong et al., "Decision Support system using artificial neural network for managing product innovation," International Journal of Computer Science Issues, vol. 9, issue 2, no. 2, March 2012.

[12] L. G. Kabari and E. Nwachukwu, "Decision Support system using decision tree and neural networks," Computer Engineering and Intelligent Systems, vol. 4, no. 7, 2013.

[13] P. Dasgupta and D. Khazanchi, "Adaptive decision support for academic course scheduling using intelligent software agents," International Journal of Technology in Teaching and Learning, pp. $63-78,2005$

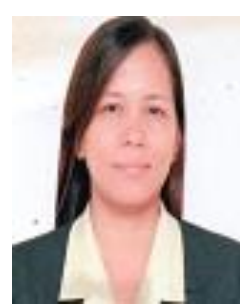

Lorna T. Soriano was born in Naga City 4400, Philippines on October 26, 1975. She is currently a doctor of information technology (DIT) student of the University of the Cordilleras, Baguio City, Philippines.

She is also working as assistant professor IV in the College of Arts and Sciences Department of the Bicol State College of Applied Sciences and Technology, Naga city, Philippines. Her research interests include machine learning, data mining and information integration.

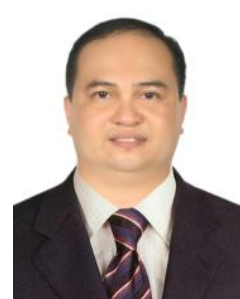

Joni Neil B. Capucao was born in Naga City, 4400, Philippines on November 5, 1973. He is currently a doctor of information technology student of the University of the Cordilleras, Baguio City, Philippines $\mathrm{He}$ graduated master of information technology at Ateneo de Naga University, Naga City, Philippines, in the year 2012.

$\mathrm{He}$ is currently working at Partido State University, Goa, Camarines Sur, 4422, Philippines with the position of assistant professor IV. He was able to published two papers in international conferences with the following titles: Linking Yesterday's Learners with Today's Technology during the $5^{\text {th }}$ Biennial Convention and 1st International Conference, held at San Carlos University, Cebu, Philippines, 2016; and ICT Building to DepEd Educators and: Learners in Partido Through Mobile Information Technology Classroom (MITC) Program during the 2016 International Higher Education Research Forum at Tagaytay, Philippines, 2016. His current research interest are on machine learning and data mining.

Mr. Capucao was awarded Faculty of the year Award and Several $1^{\text {st }}$ and $2^{\text {nd }}$ Place Kilyab Awards for Partido State University Research and Development In-house Reviews.

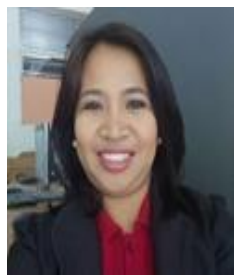

Thelma D. Palaoag is a faculty of University of the Cordilleras, College of Information Technology and Computer Science. Currently, she is with the Department Head of Computer Science. Her expertise is on natural language processing, artificial intelligence, game-based learning, data analytics, data mining and e-learning. 